\title{
Uso de vinhaça como biofertilizante: efeito na nodulação, crescimento e acúmulo de nutrientes no cultivo da soja.
}

\author{
Luis Eduardo Vieira Pinto, Fabio Fernando De Araujo
}

Universidade do Oeste Paulista - UNOESTE, Programa de Pós-Graduação em Agronomia, Presidente Prudente, SP. Email: levp@unoeste.br

\section{Resumo}

A vinhaça é um resíduo orgânico líquido proveniente do processo de fermentação para obtenção de substâncias alcoólicas, principalmente o etanol. É rica em potássio, nutriente essencial para o desenvolvimento da soja. A vinhaça é um resíduo classe II (não perigoso) caracterizado pela ausência de metais pesados e contaminantes patogênicos, por isso pode ser utilizada como biofertilizante em diversas culturas agrícolas. Objetivou-se através do presente trabalho estudar o efeito da aplicação de vinhaça na forma "in natura" e "concentrada" como fonte de potássio em substituição parcial e total na cultura da soja. O delineamento experimental utilizado foi o de blocos ao acaso, com quatro repetições. Os tratamentos foram distribuídos em função das condições da vinhaça (in natura e concentrada), aplicado na semeadura e em cobertura quando associado com a adubação mineral com cloreto de potássio na semeadura. No primeiro ano de cultivo a utilização da vinhaça promove melhores condições para nodulação e crescimento da planta. A vinhaça não afeta a nodulação da soja nos dois momentos de aplicação (semeadura e cobertura). A vinhaça pode ser utilizada como biofertilizante em substituição parcial ou total da adubação mineral com cloreto de potássio em soja, independentemente de sua forma de aplicação (in natura ou concentrada).

Palavras-chave: adubação; fertilidade; nutrição de plantas; produtividade; resíduo.

\section{Vinhaça as a biofertilizer in soybean culture: effect on nodulation, growth and nutrient aculmulation}

\begin{abstract}
Vinasse is a liquid organic waste from the fermentation process to obtain alcoholic substances, mainly ethanol. It is rich in potassium, essential nutrient for soy development. Vinasse is a class II (non-hazardous) residue characterized by the absence of heavy metals and pathogenic contaminants, so it can be used as biofertilizer in various agricultural crops. The objective of the present work was to study the effect of application of "fresh" and "concentrated" vinasse as potassium source in partial and total substitution in soybean crop. The experimental design was a randomized block design with four replications. The treatments were distributed according to the conditions of the vinasse (fresh and concentrated), applied at sowing and covering when associated with mineral fertilization with potassium chloride at sowing. In the first year of cultivation the use of vinasse promotes better conditions for nodulation and plant growth. Vinasse does not affect soybean nodulation at both application times (sowing and mulching). Vinasse can be used as biofertilizer in partial or total substitution of potassium chloride mineral fertilization in soybean, regardless of its application form (fresh or concentrated).

Keywords: fertilizing; fertility; plant nutrition; productivity; residue.
\end{abstract}

\section{Introdução}

O Brasil, por ser um país de grande atividade agrícola, é um dos que mais produzem resíduos agroindustriais (INFANTE et al., 2013).
Quando manejados de forma inadequada esses resíduos podem contaminar o solo e os corpos hídricos, gerando problemas ambientais (PEDROSA et al., 2013). Assim, é necessário 
reduzir, reciclar e reaproveitar corretamente os resíduos gerados nos mais diversos processos agroindustriais, e o uso para fins agrícolas de resíduos é uma interessante alternativa de distribuição, permitindo a reciclagem de macro e micronutrientes nos mais diversos ecossistemas.

0 principal resíduo gerado no processamento da cana-de-açúcar é denominado vinhaça. Sua composição varia de acordo com a natureza da matéria prima, tipo de levedura utilizada e eficiência do processo (FARIA et al., 2011; CHRISTOFOLETTI et al., 2013). Em média para cada litro de etanol produzido são gerados de 10 a 15 litros de vinhaça (ELIA NETO, 2016). Segundo Marques (2006) a vinhaça é composta, em sua maioria, por $93 \%$ de água e $7 \%$ de sólidos, no qual $75 \%$ correspondem à matéria orgânica. $A$ fração sólida é constituída, principalmente, de compostos orgânicos e elementos minerais, dos quais cerca de $20 \%$ é potássio. Na visão de Giachini e Ferraz (2009), o constituinte principal da vinhaça é a matéria orgânica, basicamente sob a forma de ácidos orgânicos e, em menor quantidade, por cátions como o potássio (K), cálcio (Ca) e magnésio (Mg).

A aplicação de vinhaça na lavoura, bem como a fertirrigação, é prática adotada por todas as indústrias sucroalcooleiras, com tecnologia conhecida e bem definida. Existem inúmeros ensaios que comprovam os resultados positivos obtidos na produtividade agrícola, associados à economia de adubos minerais (FARIA et al., 2011; BAFFA et al., 2009; GUSMÃO et al., 2017, BARBOSA et al., 2012). A vinhaça é comumente utilizada em sua forma in natura, porém a concentração da vinhaça através da evaporação pode ser uma alternativa para 0 setor sucroalcooleiro, pois além de diminuir o volume de vinhaça a ser transportada para o campo pode fornecer água de reuso para o processo, podendo essa água ser utilizada na lavagem de matéria prima, lavagem de pátio industrial e até mesmo lavagem de alguns equipamentos.

De acordo com Zayas et al., (2007) a prática de concentração da vinhaça consiste em retirar água desse efluente sem perda dos sólidos contidos, com consequente redução do volume, com isso, viabiliza o transporte do resíduo para áreas mais distantes. A concentração da vinhaça é normalmente realizada pelo processo de evaporação. A vinhaça concentrada adquire estabilidade biológica podendo ser armazenada por um longo período e aplicada ao solo quando necessário (REZENDE, 1984).
A aplicação de vinhaça em outras culturas vem despertando interesse dos pesquisadores, visto que este resíduo, além de fornecer nutrientes, pode ser uma fonte alternativa de fornecimento de água para contornar o déficit hídrico. De acordo com Basso et al., (2013) a vinhaça de cana-de-açúcar é rica em potássio e sua aplicação ao solo pode aumentar a disponibilidade de nutrientes bem como a produtividade das culturas.

O Brasil hoje é o segundo maior produtor de soja do mundo com uma produção aproximada na safra 2017/2018 de 114,9 milhões toneladas do grão e uma área plantada de 33,890 hectares e uma produtividade de $3,362 \mathrm{~kg} / \mathrm{ha}^{-1}$ (CONAB, 2018). Segundo Carneiro Filho e Costa (2016), o Brasil passará a ser o maior produtor mundial de soja em 2025 ultrapassando os EUA, sendo que a produção brasileira passará de uma média 89 milhões de toneladas para 136 milhões de toneladas. Levando em consideração a importância da leguminosa para a produção de alimentos no Brasil e no mundo, estudos científicos têm sidos empregados exaustivamente para se atingir altos índices de produtividade e consequentemente produção. Assim, várias tecnologias têm sido usadas, a aplicação de substâncias orgânicas, aplicados via foliar, tem sido estudada como medida auxiliar na nutrição de plantas (BENITES et al., 2006)

O potássio se destaca por ser o segundo macronutriente mais extraído pela soja, depois do nitrogênio (N), ele atua na ativação enzimática, na regulação da abertura e fechamento dos estômatos e no controle osmótico dos tecidos, dentre outras funções (MALAVOLTA, 2006; PETTER et al., 2012). Dentre os nutrientes absorvidos pela soja o $\mathrm{N}$ é o elemento que a cultura demanda em maior quantidade, em torno de $80 \mathrm{~kg} \mathrm{~N}$ para cada 1000 $\mathrm{kg}^{-1}$ de grãos produzidos (SANTOS NETO et al., 2013; LORENSINI et al., 2014). Segundo Novais et al., (2007) a aplicação de resíduos de destilarias, como a vinhaça, pode gerar benefícios na produção de culturas comuns no cerrado, como a soja. $\mathrm{O}$ fornecimento adequado de $\mathrm{K}$ para a soja promove o aumento da nodulação, do número de vagens por planta, da porcentagem de vagens com grãos, do tamanho da semente, do teor de óleo da semente e a diminuição do número de grãos enrugados (MALAVOLTA, 2006).

Por se tratar de um resíduo produzido em grande escala e possuir características para ser utilizada como biofertilizante, a vinhaça começa a 
ganhar destaque em pesquisas que buscam desenvolver e avaliar formas alternativas de se complementar a adubação química utilizada nas mais diversas culturas agrícolas. A sua utilização para estes fins tem grande importância na reciclagem de nutrientes, que aliadas às modernas técnicas de produção visam aumentar a produtividade e reduzir impactos ambientais. Dessa forma, a vinhaça possui potencial para torna-se um importante insumo para os mais diversos sistemas de produção agrícola. Entretanto faz- se necessário o desenvolvimento de pesquisas que comprovem os benefícios em culturas específicas como a soja, como também que a aplicação do resíduo não cause impactos negativos em relações microbianas no solo como a fixação biológica de Nitrogênio (FBN). A hipótese desse estudo é a de que a aplicação da vinhaça no cultivo da soja possa substituir o potássio da adubação mineral sem prejudicar a FBN. Neste contexto objetivou-se estudar o efeito da aplicação de vinhaça de cana-de-açúcar na forma in natura e concentrada como fonte de potássio em substituição parcial e total sobre os efeitos da nodulação, crescimento e acúmulo de nutrientes na cultura da soja.

\section{Material e Métodos}

O experimento foi conduzido, no período de 2015 a 2018, na Fazenda Experimental da
Universidade do Oeste Paulista - UNOESTE, localizada no município de Presidente Bernardes/SP, cujo solo é caracterizado como Argissolo Vermelho distroférrico (EMBRAPA, 2006), com relevo suave ondulado e teor de argila de $160 \mathrm{~g} \mathrm{ha}^{-1}$ na camada de $0-20 \mathrm{~m}$. 0 clima da região segundo Köppen é classificado em Cfa, com estação chuvosa no verão e estação seca no inverno. A área experimental anteriormente foi cultivada pelo consórcio de sorgo com capim por pelo período de um ano, considerando-se a implantação do experimento como área de primeiro ano para a cultura da soja. Antes da implantação do experimento foi realizada a caracterização química do solo, segundo metodologia proposta por Raij et al., (2001), na profundidade $0-0,2 \mathrm{~m}$. Os valores obtidos foram: matéria orgânica de $7,4 \mathrm{~g} \mathrm{dm}^{-3} ; \mathrm{pH}$ $\left(\mathrm{CaCl}_{2}\right.$ ) 5,7; $\mathrm{P}$ (resina) $10,1 \mathrm{mg} \mathrm{dm}^{-3} ; \mathrm{S} \mathrm{3,1} \mathrm{mg} \mathrm{dm}$ 3. H+Al e K, Ca e Mg trocáveis de 13,6; 1,4; 14,0 e 7,9 mmolc $\mathrm{dm}^{-3}$, respectivamente, $V$ de $63,0 \%$, $\mathrm{Fe}, \mathrm{Cu}, \mathrm{Mn}, \mathrm{Zn}$ e B, respectivamente, de 14,6; 4,2; 3,$5 ; 0,80$ e $0,13 \mathrm{mg} \mathrm{dm}^{-3}$.

Os dados mensais referentes às temperaturas e precipitação pluvial foram coletados durante a condução do experimento e estão apresentados na (Figura 1).

Figura 1. Condições climáticas registradas na condução do experimento.

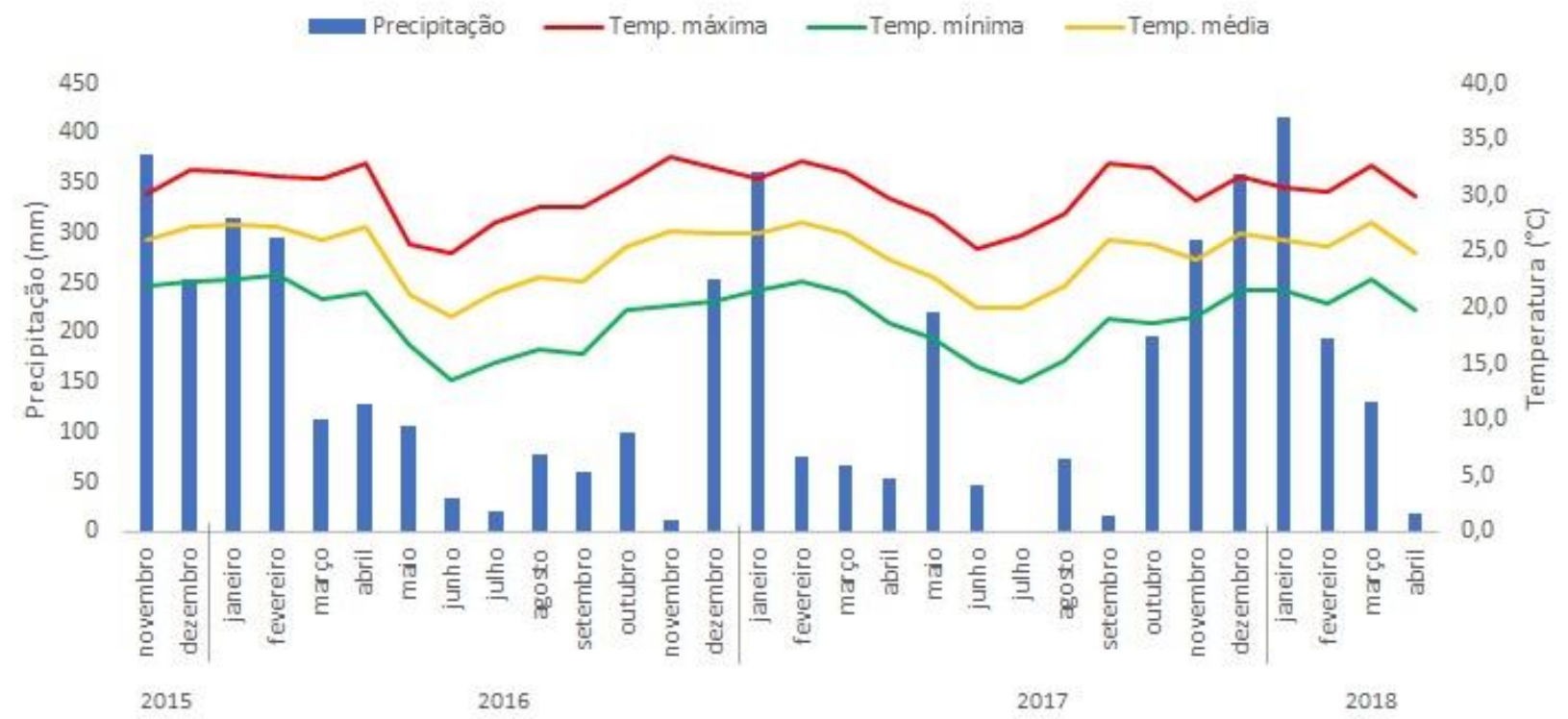

A vinhaça utilizada no experimento $\left(1^{\circ}, 2^{\circ}\right.$ e $3^{\circ}$ ano) foi obtida em usina de produção de álcool na região do Oeste Paulista. Para a obtenção da vinhaça concentrada foi utilizado o processo de evaporação realizado no Centro de Tecnologia de Alimentos da UNOESTE, através do 
aquecimento em tanques de aço inox constituídos de serpentinas internas para a circulação de vapores oriundos de caldeira. Para uso no experimento a vinhaça foi aplicada na forma in natura e na forma concentrada, com redução do volume em cerca de $70 \%$. As amostras de vinhaça in natura e concentrada foram submetidas a análise química, para caracterização nutricional do resíduo e seus resultados estão descritos na (Tabela 1 ).

Tabela 1. Composição química das diferentes amostras de vinhaça utilizadas como biofertilizante.

\begin{tabular}{|c|c|c|c|c|c|c|c|c|c|c|}
\hline \multirow{3}{*}{$\begin{array}{c}\text { Amostras } \\
\text { Vinhaça }\end{array}$} & \multicolumn{6}{|c|}{ Macronutrientes } & \multicolumn{4}{|c|}{ Micronutrientes } \\
\hline & $N$ & $P$ & $\mathrm{~K}$ & $\mathrm{Ca}$ & $\mathrm{Mg}$ & $S$ & $\mathrm{Cu}$ & $\mathrm{Fe}$ & $\mathrm{Mn}$ & $\mathrm{Zn}$ \\
\hline & & & $---(g$ & & & & & $---(m$ & & \\
\hline $\mathrm{VI}-1^{\circ}$ ano & 0,2 & 0,03 & 0,6 & 0,3 & 0,1 & 0,1 & 1,2 & 18 & 1,3 & 0,8 \\
\hline VC - 10 ano & 0,8 & 0,14 & 4,3 & 1,6 & 1,2 & 0,3 & 2,3 & 119,3 & 18,8 & 3,4 \\
\hline VI - 2ㅇ ano & 0,3 & 0,05 & 8,8 & 2,1 & 2,4 & 0,1 & 94,3 & 1373,3 & 444 & 164,3 \\
\hline VC - 29 ano & 1,8 & 0,29 & 113,83 & 8,1 & 13,8 & 0,8 & 234,7 & 6830,7 & 1649,7 & 16,77 \\
\hline
\end{tabular}

$\mathrm{VI}=$ Vinhaça in natura; $\mathrm{VC}=$ Vinhaça concentrada.

Para o terceiro ano do experimento foi utilizada a mesma amostra de vinhaça referente ao segundo ano de coleta. Devido a sua maior concentração de nutrientes e baixo volume de aplicação, não houve a necessidade de coletar outras amostras junto a usina, as mesmas foram acondicionadas de um ano para o outro sob condições de refrigeração para garantir sua qualidade na hora da aplicação.

O delineamento experimental utilizado foi o de blocos ao acaso, com quatro repetições. Os tratamentos foram compostos por cinco formas de adubação, sendo: T1 (tratamento controle) $=250 \mathrm{~kg} \mathrm{ha}^{-1}$ do adubo 08-28-16 na semeadura $+40 \mathrm{~kg}$ de cloreto de potássio em cobertura; $\mathrm{T} 2=250 \mathrm{~kg} \mathrm{ha}^{-1}$ do adubo 08-28-16 na semeadura + vinhaça in natura em cobertura como fonte de adubação potássica; T3 $=250 \mathrm{~kg}$ ha ${ }^{-1}$ do adubo 08-28-16 na semeadura + vinhaça concentrada em cobertura como fonte de adubação potássica; T4 = Nitrogênio (ureia) e Fósforo (superfosfato triplo) na semeadura, vinhaça in natura 10 dias após a semeadura (fonte de potássio) + vinhaça in natura em cobertura; T5 = Nitrogênio (ureia) e Fósforo (superfosfato triplo) na semeadura, vinhaça concentrada 10 dias após a semeadura (fonte de potássio) + vinhaça concentrada em cobertura.

A vinhaça in natura foi aplicada com o auxílio do conjunto trator/pulverizador de barras; já a vinhaça concentrada em razão do seu menor volume foi aplicada através de pulverizador com capacidade para 10 litros, foi aplicado sobre a planta e sobre o solo na entrelinha da soja, sendo a vinhaça distribuída de forma homogênea de modo a padronizar o tempo de molhamento em quatro a cinco minutos. As unidades experimentais possuíam 8 metros de comprimento por 2,7 metros de largura com 4 repetições por tratamento.

A semeadura da soja foi realizada no dia 30 de novembro de 2015, utilizando sementes inoculadas da variedade AS 3610 IPRO (Intacta RR2 PRO). A semeadura foi realizada em sete linhas, com espaçamento entre linhas de quarenta e cinco centímetros, sendo regulada para distribuir 12 sementes por metro linear. A semeadora possuía acoplado à sua estrutura um equipamento para a inoculação direta no sulco de semeadura. Foi utilizado o inoculante Gelfix $5^{\circledR}$ contendo a concentração de $5 \times 109$ UFC/ml (unidade de formação de colônias) na dose de $800 \mathrm{ml}$ de inoculante por hectare.

A adubação de semeadura constou da aplicação de $20 \mathrm{~kg}$ de $\mathrm{N}$ por ha ${ }^{-1}, 70 \mathrm{~kg}$ de $\mathrm{P}_{2} \mathrm{O}_{5}$ por $\mathrm{ha}^{-1}$ e $40 \mathrm{~kg}$ de $\mathrm{K}_{2} \mathrm{O}$ por $\mathrm{ha}^{-1}$. Utilizando cálculos agronômicos de conversão, baseando-se no teor de $\mathrm{K}_{2} \mathrm{O}$ utilizado na adubação de semeadura, obteve-se o equivalente a $33,3 \mathrm{~kg}$ de $\mathrm{K}$ por hectare na semeadura. Para o primeiro ano de experimento a aplicação da vinhaça na semeadura foi realizada baseando-se na quantia de $33,3 \mathrm{~kg}$ de $\mathrm{K}$ por ha ${ }^{-1}$ o que de acordo com os resultados obtidos na análise química da vinhaça resultou na aplicação de 120 litros de vinhaça in natura e 16,75 litros de vinhaça concentrada por parcela. Para a adubação de cobertura realizada trinta e cinco dias após a semeadura, a aplicação foi fundamentada no teor de $\mathrm{K}$ existente no $\mathrm{KCl}$ (cloreto de potássio). Utilizando $40 \mathrm{~kg}$ de $\mathrm{KCl}$ por $\mathrm{ha}^{-1}$, têm-se então $24 \mathrm{~kg}$ de $\mathrm{K}_{2} \mathrm{O}$ por $\mathrm{ha}^{-1}$, equivalente a $20 \mathrm{~kg}$ de $\mathrm{K}$ por ha ${ }^{-1}$ o que de acordo 
com os resultados obtidos na análise química da vinhaça resultou na aplicação de 72 litros de vinhaça in natura e 10,05 litros de vinhaça concentrada por parcela.

Nos tratamentos 4 e 5 não foram aplicados na semeadura o adubo 08-28-16 para não haver interferência do $\mathrm{K}_{2} \mathrm{O}$ existente na formulação, dessa forma foi distribuído junto com a semente apenas os elementos nitrogênio na forma de ureia e fósforo $\left(\mathrm{P}_{2} \mathrm{O}_{5}\right)$ na forma de superfosfato triplo, respeitando as quantidades aplicadas nos demais tratamentos, dez dias após a semeadura a vinhaça in natura e concentrada foram aplicadas nas parcelas como fonte de adubação potássica.

Houve aplicação de água nas parcelas onde não foram aplicados a vinhaça através de irrigação realizada com trator/pulverizador de barras para desviar a hipótese de que a água oriunda da vinhaça pudesse influenciar nos resultados obtidos.

Para as avaliações, foram consideradas as cinco linhas centrais de cada unidade experimental, desprezando-se 1,0 metro nas extremidades das parcelas. Foram avaliados os componentes de produção da soja: nodulação, massa seca da parte aérea, população de plantas (estande), nitrogênio acumulado e potássio acumulado.

Aos 60 dias após a semeadura foram coletadas dez plantas de soja por repetição das linhas centrais de forma aleatória, com quatro repetições, totalizando 40 plantas por tratamento. Essas plantas foram encaminhadas para laboratório para avaliação do número de nódulos por planta. Para a análise da massa seca da parte aérea as plantas foram submetidas a secagem por 72 horas em estufa de circulação de ar forçada com temperatura de $65^{\circ} \mathrm{C}$. Após a pesagem as amostras referentes a cada repetição foram submetidas a análise química foliar para a determinação do teor de nitrogênio e potássio presente nas plantas. Passados noventa dias da semeadura foi realizado a contagem de plantas em 10 metros lineares, a partir destes valores multiplicava-se por 22.222,22 (m $\left.\mathrm{m}^{-1} \mathrm{ha}^{-1}\right)$ para obtenção do estande de plantas, encerrando assim o ciclo da cultura aos 122 dias.

Para o segundo ano do experimento foi utilizada a mesma área referente ao primeiro ano, realizou-se a semeadura da soja no dia 07 de dezembro de 2016, respeitando a mesma metodologia utilizada no ano anterior, porém agora utilizando sementes inoculadas da variedade BRS 1003 IPRO (Intacta RR2 PRO) e a dose de $400 \mathrm{ml}$ de inoculante Gelfix $5^{\circledR}$ por hectare.

A adubação de semeadura constou da aplicação de $20 \mathrm{~kg}$ de $\mathrm{N}$ por ha ${ }^{-1}, 70 \mathrm{~kg}$ de $\mathrm{P}_{2} \mathrm{O}_{5}$ por ha ${ }^{-1}$ e $40 \mathrm{~kg}$ de $\mathrm{K}_{2} \mathrm{O}$ por ha ${ }^{-1}$. Utilizando cálculos agronômicos de conversão, baseando-se no teor de $\mathrm{K}_{2} \mathrm{O}$ utilizado na adubação de semeadura, obteve-se o equivalente a 33,3 kg de $K$ por hectare na semeadura. A aplicação da vinhaça na semeadura foi realizada baseando-se na quantia de $33,3 \mathrm{~kg}$ de $\mathrm{K}$ por $\mathrm{ha}^{-1}$ o que de acordo com os resultados obtidos na análise química da vinhaça $\left(2^{\circ}\right.$ ano) resultou na aplicação de 8,2 litros de vinhaça in natura e 0,63 litros de vinhaça concentrada por parcela, aplicadas doze dias após a semeadura. Para a adubação de cobertura realizada quarenta dias após a semeadura, a aplicação foi fundamentada no teor de $\mathrm{K}$ existente no $\mathrm{KCl}$ (cloreto de potássio). Utilizando $40 \mathrm{~kg}$ de $\mathrm{KCl}$ por ha ${ }^{-1}$, têm-se então 24 $\mathrm{kg}$ de $\mathrm{K}_{2} \mathrm{O}$ por $\mathrm{ha}^{-1}$, equivalente a $20 \mathrm{~kg}$ de $\mathrm{K}$ por $\mathrm{ha}^{-1}$ o que de acordo com os resultados obtidos na análise química da vinhaça resultou na aplicação de 4,9 litros de vinhaça in natura e 0,38 litros de vinhaça concentrada por parcela, devido ao baixo volume a ser aplicado a vinhaça concentrada aplicada na semeadura e em cobertura foi misturada em água totalizando uma solução de 2 litros.

Os tratamentos no segundo ano foram realizados respeitando a mesma disposição do primeiro ano do experimento, a única exceção foi em relação ao modo de aplicação da vinhaça, tendo em vista que as aplicações das dosagens de vinhaça in natura e concentrada tanto na semeadura quanto na cobertura foram realizadas através de um pulverizador costal elétrico, que permite uma maior qualidade de aplicação devido a padronização do volume e tamanho de gotas pela pressão constante regulada no aparelho.

Para as avaliações de componentes de produção nodulação, massa seca da parte aérea, população de plantas (estande), nitrogênio acumulado e potássio acumulado, respeitou-se a mesma metodologia utilizada no primeiro ano do experimento, encerrando o ciclo da cultura aos 110 dias.

Para o terceiro ano do experimento a área utilizada foi a mesma referente aos anos anteriores, realizou-se a semeadura da soja no dia 28 de dezembro de 2017, utilizando sementes inoculadas da variedade NS 6700 IPRO (Nidera). A 
semeadura foi realizada obedecendo os mesmos critérios do segundo ano do experimento. Respeitou-se também os mesmos procedimentos dos anos anteriores para as avaliações dos componentes de produção da soja.

Após as coletas de dados os mesmos foram submetidos ao teste de Levene para verificação da homogeneidade das variâncias e ao teste de Shapiro-Wilk para verificar a normalidade dos dados. Como ambos os pressupostos foram atendidos, os dados foram submetidos à análise de variância (ANOVA, $p<0,05)$. As médias dos tratamentos foram comparadas pelo teste de Tukey com nível de significância estatística com limite de $5 \%(p<0,05)$ com auxílio do programa SISVAR (FERREIRA, 2011). Os gráficos foram confeccionados através do programa Microsoft Office Excel versão 2013.

\section{Resultados e Discussão}

Houve aumento expressivo na nodulação das plantas, de forma geral, a partir do segundo ano do experimento. Segundo Zilli et al., (2008) mesmo a inoculação sendo uma prática adotada regularmente na soja, ocorrem casos de falha na nodulação das plantas na lavoura, especialmente em áreas de primeiro cultivo de soja, o que na maioria das vezes compromete o rendimento de grãos.

Mesmo com pouca nodulação encontrada no primeiro ano de cultivo (Figura 2), nota-se que os tratamentos que receberam a aplicação da vinhaça, na semeadura e em cobertura, se destacaram em função da quantidade de nódulos por planta, efeito esse que também foi verificado nos anos seguintes onde a nodulação foi consistente em todos os tratamentos. Esses resultados podem estar relacionados com o aumento do teor de matéria orgânica no solo resultante da aplicação do resíduo, pois segundo Benizri et al., (2001) a sobrevivência de bactérias na rizosfera possui correlação positiva com o teor de matéria orgânica e de nitrogênio no solo, além de promover a sustentabilidade biológica e a produtividade nos ecossistemas (SCHLOTER et al., 2003). De acordo com Giachini e Ferraz (2009), a presença da matéria orgânica na vinhaça proporciona melhoria nas propriedades biológicas do solo, com aumento da microflora do solo, além do aumento do poder de retenção de água, fator esse que pode influenciar diretamente na formação dos nódulos na planta, reafirmando o que já foi relatado por Souza et al., (2015).

Figura 2. Nodulação da soja $\left(\mathrm{N}^{\circ}\right.$ de nódulos $\left.\mathrm{pl}^{-1}\right)$ em função dos tratamentos nos três anos de experimentação. $\mathrm{T} 1=250 \mathrm{~kg} \mathrm{ha}^{-1}$ de 08-28-16 na semeadura $+40 \mathrm{~kg} \mathrm{de} \mathrm{KCl} \mathrm{em} \mathrm{cobertura} \mathrm{como} \mathrm{fonte} \mathrm{de}$ potássio; $\mathrm{T} 2=250 \mathrm{~kg} \mathrm{ha}^{-1}$ de 08-28-16 na semeadura + (vinhaça in natura) em cobertura como fonte de potássio; T3 $=250 \mathrm{~kg} \mathrm{ha}^{-1}$ de 08-28-16 na semeadura + (vinhaça concentrada) em cobertura como fonte de potássio; T4 = Nitrogênio + Fósforo + vinhaça in natura na semeadura + (vinhaça in natura) em cobertura como fonte de potássio; $T 5$ = Nitrogênio + Fósforo + vinhaça concentrada na semeadura + (vinhaça concentrada) em cobertura como fonte de potássio.

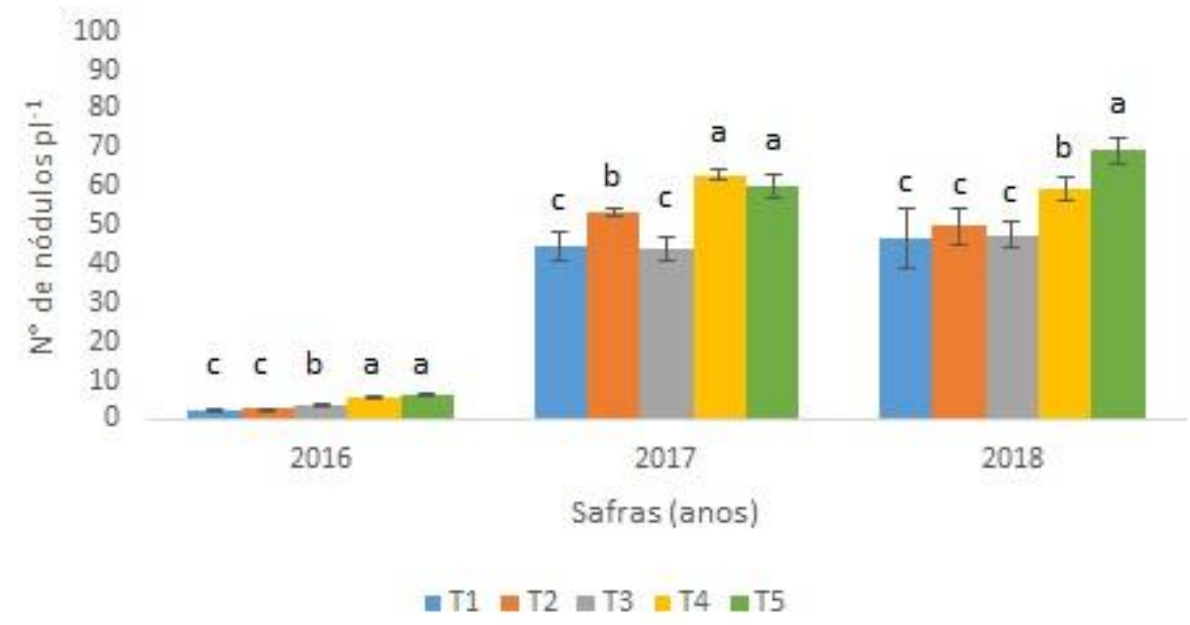


Na produção de massa seca da parte aérea (Figura 3) nota-se que para o primeiro ano de cultivo (2016), houve um incremento na faixa de $38 \%$ de massa da soja para todos os tratamentos onde utilizou-se a vinhaça. Nos anos seguintes os tratamentos se equivaleram nesse quesito. Este efeito no primeiro ano pode ser devido à ação benéfica proporcionada pela adição da vinhaça sobre a microbiologia e nutrição da planta conforme já relatado por Pravuschi et al., (2010). Farinelli et al., (2017) estudando o emprego de resíduos sucroalcoleiros como fonte de adubação em graníferas, verificaram que o uso de vinhaça concentrada no milho proporcionou a cultura ganhos significativos na massa seca da parte aérea das plantas, resultados estes que não foram observados nos tratamentos que não receberam a aplicação da vinhaça. O uso da vinhaça como promotora de crescimento da parte aérea de plantas também foi observado por Basso et al., (2013) quando estudaram a sua aplicação como fonte de potássio em resposta a sucessão de culturas gramíneas, os autores concluíram que a aplicação de doses até $100 \mathrm{~m}^{3}$ de vinhaça promoveram maiores produtividades de matéria seca da parte aérea da aveia preta e milho silagem (forragem). Resultados similares foram observados por Martins et al., (2013) os autores relataram que o potássio presente na vinhaça do ponto de vista fisiológico favoreceu a divisão e o crescimento celular, bem como promovendo o aumento da massa das plantas de milho.

Figura 3. Massa seca da parte aérea $\left(\mathrm{g} \mathrm{pl}^{-1}\right)$ em função dos tratamentos nos três anos de experimentação. $\mathrm{T} 1=250 \mathrm{~kg} \mathrm{ha}^{-1}$ de 08-28-16 na semeadura $+40 \mathrm{~kg}$ de $\mathrm{KCl}$ em cobertura como fonte de potássio; $\mathrm{T} 2=250$ $\mathrm{kg} \mathrm{ha}^{-1}$ de 08-28-16 na semeadura + (vinhaça in natura) em cobertura como fonte de potássio; T3 = $250 \mathrm{~kg}$ $\mathrm{ha}^{-1}$ de 08-28-16 na semeadura + (vinhaça concentrada) em cobertura como fonte de potássio; T4 = Nitrogênio + Fósforo + vinhaça in natura na semeadura + (vinhaça in natura) em cobertura como fonte de potássio; T5 = Nitrogênio + Fósforo + vinhaça concentrada na semeadura + (vinhaça concentrada) em cobertura como fonte de potássio.

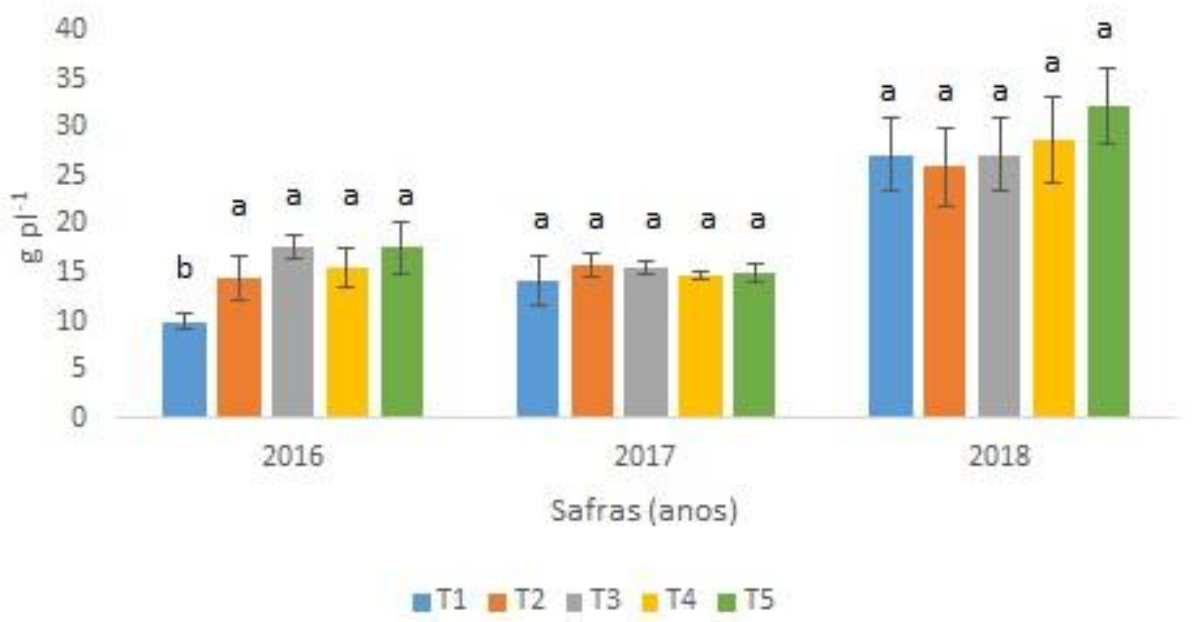

O estande final de plantas (Figura 4) foi influenciado pelos tratamentos com vinhaça apenas no primeiro ano de cultivo, não diferindo significativamente do tratamento apenas com adubação mineral (T1) nos anos seguintes. Segundo a Embrapa (2004), populações de 240.000 a 400.000 plantas por hectare são aceitáveis em função da cultivar, regime de chuvas, data de semeadura e fertilidade do solo. Dos resultados obtidos no primeiro ano de cultivo apenas o T1 não atingiu essa faixa, diferindo estatisticamente em menor quantidade de plantas por hectare. 0 estande final de plantas aumentou em mais de $20 \%$ nos tratamentos com vinhaça no primeiro ano de cultivo. Resultados semelhantes foram obtidos por Lemainski e Silva (2006) avaliando parâmetros técnicos e econômicos de resposta da soja à aplicação de resíduos orgânicos em comparação ao uso de fertilizante mineral em doses equivalentes de $\mathrm{N}$ $\mathrm{P}-\mathrm{K}$, concluíram que o aproveitamento do resíduo orgânico como fertilizante pode ser viável em 
termos agronômicos e econômicos, mostrandose $18 \%$ mais eficiente do que o fertilizante mineral como fonte de nutrientes na cultura da soja. Para o segundo ano de cultivo todos os tratamentos obtiveram um estande superior a 240.000 plantas, porém, sem apresentar diferença estatística. No terceiro ano de cultivo, houve uma redução geral do estande de plantas atingido valor abaixo do preconizado pela
Embrapa (2004), fato este que pode estar associado com a época de semeadura da soja, visto que a mesma foi realizada após o período recomendado para a região. Porém, segundo Vega et al., (2000), a soja é eficiente em apresentar índices estáveis de colheita a despeito de estandes desuniformes.

Figura 4. Estande (Número de plantas ha ${ }^{-1}$ ) em função dos tratamentos nos três anos de experimentação. $\mathrm{T} 1=250 \mathrm{~kg} \mathrm{ha}^{-1}$ de 08-28-16 na semeadura + $40 \mathrm{~kg}$ de $\mathrm{KCl}$ em cobertura como fonte de potássio; $\mathrm{T} 2=250$ $\mathrm{kg} \mathrm{ha}^{-1}$ de 08-28-16 na semeadura + (vinhaça in natura) em cobertura como fonte de potássio; T3 = $250 \mathrm{~kg}$ $\mathrm{ha}^{-1}$ de 08-28-16 na semeadura + (vinhaça concentrada) em cobertura como fonte de potássio; T4 = Nitrogênio + Fósforo + vinhaça in natura na semeadura + (vinhaça in natura) em cobertura como fonte de potássio; T5 = Nitrogênio + Fósforo + vinhaça concentrada na semeadura + (vinhaça concentrada) em cobertura como fonte de potássio.

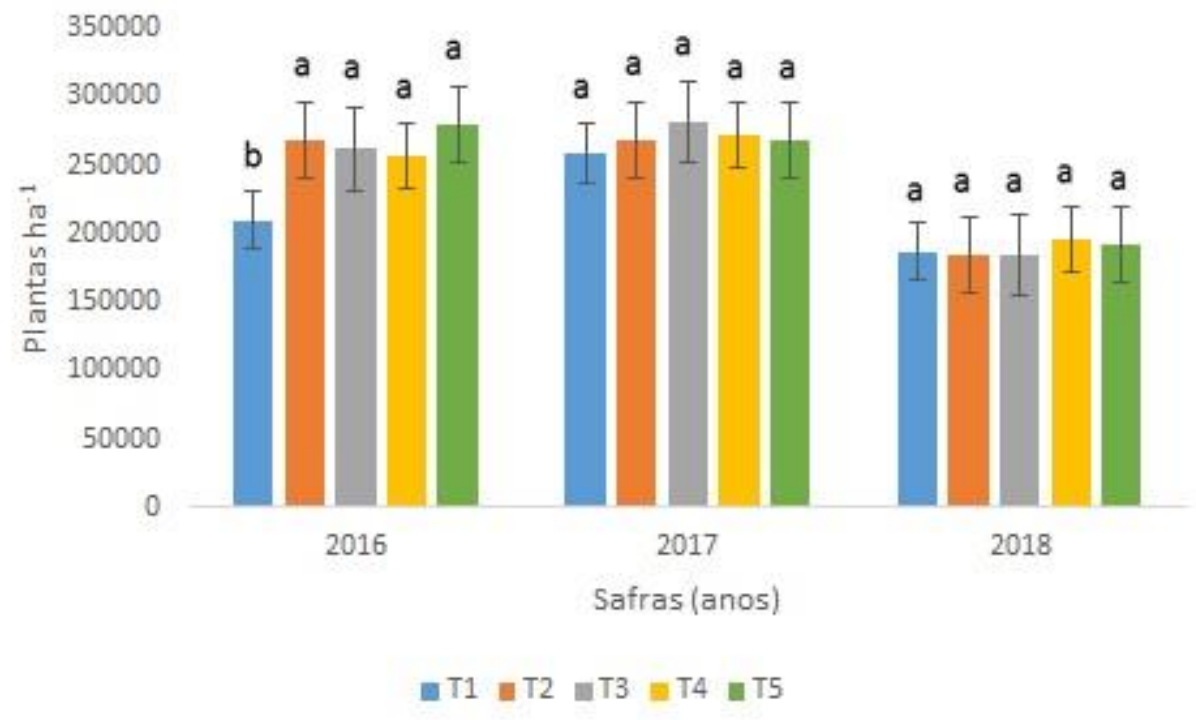

Houve um aumento crescente no acúmulo de nitrogênio no decorrer dos anos em todos os tratamentos (Figura 5). No terceiro ano de cultivo, pode ser destacada que o uso de vinhaça em dois momentos (semeadura e cobertura) proporcionou aumento considerável no acúmulo de nitrogênio na planta. Este aumento pode ser explicado em parte pela maior nodulação das plantas e fornecimento indireto de $\mathrm{N}$ pela adição do resíduo. Tendo em vista que o nitrogênio está presente na vinhaça, predominantemente na forma orgânica, e a mineralização é a primeira transformação biológica que ocorre no solo
(CUNHA et al., 1981; ALFAIA, 2006; CANTARELLA, 2007) a sua liberação no solo ocorre de forma gradual com aumentos crescentes ao longo dos anos. Os resultados obtidos no terceiro ano de cultivo, destoam dos resultados obtidos por Xavier (2012), a autora relata que o uso de vinhaça natural e vinhaça biodigerida concentrada não induziram diferenças significativas nos teores de nitrogênio acumulado na parte aérea da cultura de cana-de-açúcar em relação ao tratamento testemunha. 
Figura 5. Nitrogênio acumulado $\left(\mathrm{g} \mathrm{N} \mathrm{pl}^{-1}\right)$ em função dos tratamentos nos três anos de experimentação. T1 $=250 \mathrm{~kg} \mathrm{ha}^{-1}$ de 08-28-16 na semeadura $+40 \mathrm{~kg}$ de KCl em cobertura como fonte de potássio; $\mathrm{T} 2=250 \mathrm{~kg}$ $\mathrm{ha}^{-1}$ de 08-28-16 na semeadura + (vinhaça in natura) em cobertura como fonte de potássio; $\mathrm{T} 3=250 \mathrm{~kg} \mathrm{ha}^{-1}$ de 08-28-16 na semeadura + (vinhaça concentrada) em cobertura como fonte de potássio; T4 = Nitrogênio + Fósforo + vinhaça in natura na semeadura + (vinhaça in natura) em cobertura como fonte de potássio; T5 = Nitrogênio + Fósforo + vinhaça concentrada na semeadura + (vinhaça concentrada) em cobertura como fonte de potássio.

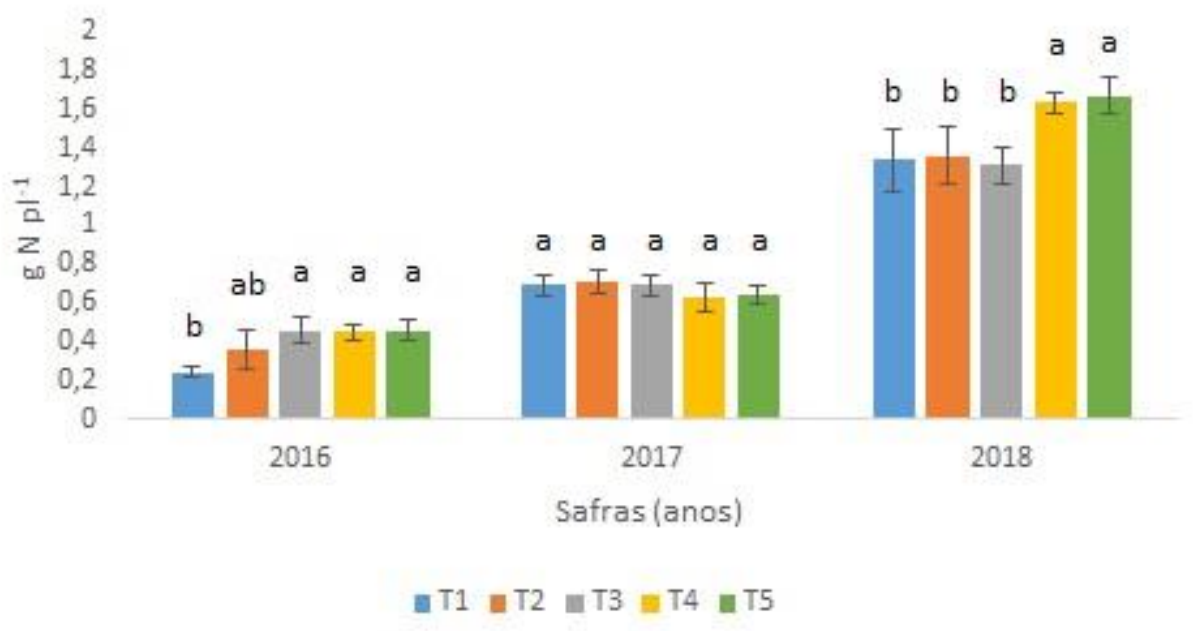

No primeiro e terceiro ano de cultivo ocorreu maior acúmulo de potássio nas plantas nos tratamentos que utilizaram a vinhaça como fonte de potássio. Isto confirma o potencial do resíduo como fonte de potássio para soja. 0 acúmulo de potássio no tecido vegetal também foi verificado por Nascimento et al. (2017) quando aplicou vinhaça no cultivo de alfafa. 0 aumento de potássio na planta é importante para o sistema de produção pois o potássio apresenta alta mobilidade e não faz parte de nenhum composto orgânico na planta. Assim, após a colheita ou senescência das plantas, o potássio presente na fitomassa é liberado rapidamente ao solo em forma prontamente disponível para as culturas Raij et al., (1997), o que caracteriza a palhada como um reservatório expressivo de potássio em curto prazo no sistema de plantio direto (ROSOLEM et al., 2003; FOLONI; ROSOLEM, 2004). A ausência de efeito significativo no segundo ano pode ser devida a fatores climáticos adversos pois ocorreu baixa precipitação nos meses de cultivo da soja (Figura 1). Isto pode ter reduzido o crescimento da soja e em consequência o menor acúmulo de potássio.

O comportamento em relação ao acúmulo de potássio $(K)$ em comparação ao de nitrogênio são muito similares principalmente nos dois primeiros anos de cultivo da soja. O fornecimento de potássio para as plantas estimula o aproveitamento do nitrogênio, possibilitando que sua absorção, assimilação e, consequentemente, a produtividade sejam aumentadas (VIANA, 2007; VIANA; KIEHL, 2010). Ueno et al., (2013) ao estudarem o efeito da aplicação de vinhaça em hortaliças, verificaram que os teores de potássio acumulado nas folhas de alface eram estatisticamente maiores nos tratamentos submetidos a aplicação de vinhaça "in natura" e vinhaça concentrada biodigerida do que quando comparado com o tratamento testemunha, porém, não havendo diferença estatística entre os dois diferentes tipos de vinhaça aplicada. 
Figura 6. Potássio acumulado $\left(\mathrm{g} \mathrm{K} \mathrm{pl}^{-1}\right)$ em função dos tratamentos nos três anos de experimentação. $\mathrm{T} 1=$ $250 \mathrm{~kg} \mathrm{ha}^{-1}$ de 08-28-16 na semeadura $+40 \mathrm{~kg}$ de KCl em cobertura como fonte de potássio; $\mathrm{T} 2=250 \mathrm{~kg}$ ha ${ }^{1}$ de 08-28-16 na semeadura + (vinhaça in natura) em cobertura como fonte de potássio; $\mathrm{T3}=250 \mathrm{~kg} \mathrm{ha}{ }^{-1}$ de 08-28-16 na semeadura + (vinhaça concentrada) em cobertura como fonte de potássio; T4 = Nitrogênio + Fósforo + vinhaça in natura na semeadura + (vinhaça in natura) em cobertura como fonte de potássio; $T 5=$ Nitrogênio + Fósforo + vinhaça concentrada na semeadura + (vinhaça concentrada) em cobertura como fonte de potássio.

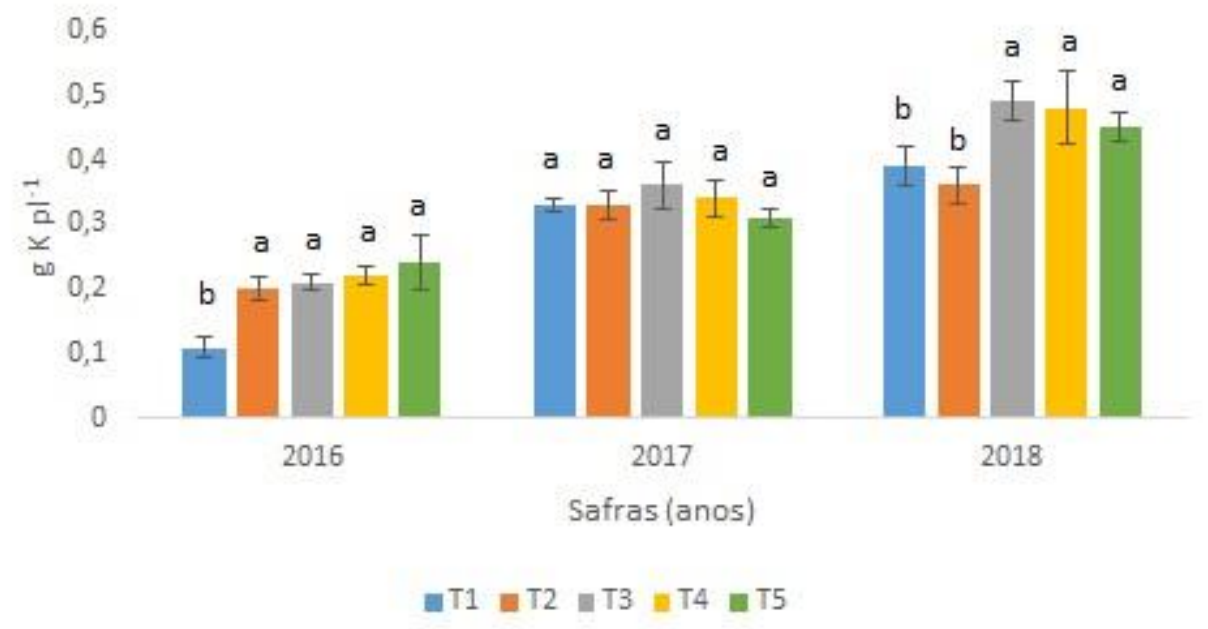

A partir de uma análise agronômica o uso da vinhaça como substituição total ou parcial da adubação potássica mostrou-se viável para o cultivo da soja. Ocorreram ganhos na nutrição das plantas e também não afetou a nodulação das plantas. Com base nesses resultados pode ser desenvolvidos novos estudos com a aplicação do resíduo em outros locais. Também faz-se necessários estudos de viabilidade econômica para uso desse resíduo considerando a logística e processamento do mesmo.

\section{Conclusões}

No primeiro ano de cultivo a utilização da vinhaça promove melhores condições para nodulação e crescimento da planta.

A vinhaça não afeta a nodulação da soja nos dois momentos de aplicação (semeadura e cobertura).

A aplicação da vinhaça no solo aumenta o acúmulo de potássio e nitrogênio na soja.

A vinhaça pode ser utilizada como biofertilizante em substituição parcial ou total da adubação mineral com cloreto de potássio em soja, independentemente de sua forma de aplicação (in natura ou concentrada).

\section{Referências}

ALFAIA, S. S. Caracterização e distribuição das formas do nitrogênio orgânico em três solos da
Amazônia Central. Acta Amazônica, v.36, n.2, p. 135-140 2006. https://doi.org/10.1590/S004459672006000200001

BAFFA, D. C. F.; FREITAS, R. G. de.; BRASIL, R. P. C. do. O uso da vinhaça na cultura da cana-deaçúcar. Revista Nucleus, Ituverava, edição especial, p. 1-16, 2009.

BARBOSA, E. A. A; ARRUDA, F. B.; PIRES, R. C. M.; SILVA, T. J. A. DA; SAKAI, E. Cana-de-açúcar com vinhaça e adubos minerais via irrigação por gotejamento subsuperficial: Ciclo da cana-planta. Revista Brasileira de Engenharia Agrícola e Ambiental, Campina Grande, v.16, n.9, p. 952958, 2012. https://doi.org/10.1590/S1415$\underline{43662012000900005}$

BASSO, C. J.; SANTI, A. L.; LAMEGO, F. P.; SOMAVILHA, L.; BRIGO, T. J. Vinhaça como fonte de potássio: resposta da sucessão aveiapreta/milho silagem/milho safrinha e alterações químicas do solo na Região Noroeste do Rio Grande do Sul. Ciência. Rural, Santa Maria, v.43, n.4, p. 596-602, 2013. http://dx.doi.org/10.1590/S010384782013000400006.

BENITES, V. D. M.; POLIDORO J; MENEZES C; BETTA M. Aplicação foliar de fertilizante 
organomineral e soluções de ácido húmico em soja sob plantio direto. Rio de Janeiro: Embrapa Solos, 2006. 6 p. (Série Embrapa Solos. Circular Técnica, 35).

BENIZRI, E.; BAUDOIN, E.; GUCKERT, A. Root colonization by inoculated plant growthpromoting rhizobacteria. Biocontrol Science and Technology, v.11, n.5, p. 557-574, 2001.

\section{https://doi.org/10.1080/09583150120076120}

BRASIL. Companhia Nacional De Abastecimento (CONAB). Produção de $\mathbf{2 3 0}$ milhões de $\mathbf{t}$ de grãos é segundo recorde. Brasília: CONAB, 2018. Disponível em:

https://www.conab.gov.br/index.php/componen $\mathrm{t} /$ content/article?id=2301. Acesso em: $20 \mathrm{abr}$. 2019.

CANTARELLA, H. Nitrogênio. In: NOVAIS, R. F.; ALVAREZ, V. H. V.; BARROS, N. F.; FONTES, R. L. F.; CENTARUTTI, R. B.; NEVES, J. C. L. Fertilidade do solo. Viçosa, MG: Sociedade Brasileira de Ciência do Solo, 2007. p. 375-470.

CARNEIRO FILHO, A.; COSTA, K. A expansão da soja no Cerrado: caminhos para a ocupação do território, uso do solo e produção sustentável. São Paulo: INPUT, 2016. 30 p.

CUNHA, R. C. A.; COSTA, A. C. S.; MASET FILHO, B.; CASARINI, D. C. P. Effects of irrigation with vinasse and dynamics of its constituents in the soil: I - physical and chemical aspects. Water Science Technology, v.19, n.8, p. 155-165, 1981. https://doi.org/10.2166/wst.1987.0054

CHRISTOFOLETTI, C. A.; ESCHER, J. P.; CORREIA, J. E.; MARINHO, J. F. U.; FONTANETTI, C. S. Sugarcane vinasse: environmental implications of its use. Waste management, v.33, n.12, p. 27522761, 2013.

https://doi.org/10.1016/j.wasman.2013.09.005

ELIA NETO, A. Estado da arte da vinhaça. Campinas: Única, 2016. 38 p.

EMBRAPA. Centro Nacional de Pesquisa de Solos. Sistema brasileiro de classificação de solos. 2 . ed. Rio de Janeiro: Embrapa Solos, 2006.
EMBRAPA. Tecnologias de produção de soja Paraná 2005. Londrina: Embrapa Soja, 2004. 224p.

FARIA, A. A. A.; DUDA, R. M.; OLIVEIRA, R. A. Concentração da Vinhaça e Reaproveitamento da Água. In: IV SEMANA DE TECNOLOGIA DO CURSO DE BIOCOMBUSTÍVEIS DA FACULDADE DE TECNOLOGIA DE JABOTICABAL. 2011, Jaboticabal. Anais [...]. Jaboticabal: FATEC, 2011. 4 p.

FARINELLI, R.; MUSSI, L. E.; MANCINI, R. T. Uso de resíduos agroindustriais de cana-de-açúcar na adubação da cultura do milho. Revista Científica Multidisciplinar do Centro Universitário da FEB, Barretos, v. 13, n. 2, p. 65-73, 2017.

https://doi.org/10.4322/1980-0029.162017

FERREIRA, D. F. Sisvar: a computer statistical analysis system. Ciência e Agrotecnologia, Lavras, v. 35, n.6, p. 1039-1042, 2011.

https://doi.org/10.1590/S1413-

$\underline{70542011000600001}$

FOLONI, J. S. S.; ROSOLEM, C. A. Potassium balance in soybean grown under no-till. In: INTERNATIONAL CROP SCIENCE CONGRESS, 4., 2004, Brisbane. Anais [...]. Austrália: ICSC, 2004. $14 \mathrm{p}$.

GIACHINI, C. F.; FERRAZ, M. V. Benefícios da utilização de vinhaça em terras de plantio de cana-de-açúcar: revisão de literatura. Revista Científica Eletrônica de Agronomia, Garça, v.3, n.1, p. 1-15, 2009.

GUSMÃO, S. F. A.; SATO, S. S.; BERTOLLI, S. C. A viabilidade dos custos de utilização da vinhaça no cultivo de cana-de-açúcar. Colloquium Socialis, Presidente Prudente, v.1, n.2, p. 539-543, 2017. https://doi.org/10.5747/cs.2017.v01.nesp2.s0189

INFANTE, J.; SELANI, M. M.; TOLEDO, N. M. V. de.; SILVEIRA-DINIZ, M. F.; ALENCAR, S. M. de.; SPOTO, M. H. F. Atividade antioxidante de resíduos agroindustriais de frutas tropicais. Alimentos e Nutrição Araraquara. Araraquara, v. 24, n.1, p. 87-91, 2013.

LEMAINSKI, J.; SILVA, J. E. da. Avaliação agronômica e econômica da aplicação de biossólido na produção de soja. Pesquisa Agropecuária Brasileira, Brasília, v.41, n.10, p. 
1477-1484, 2006. https://doi.org/10.1590/S0100$\underline{204 \times 2006001000004}$

LORENSINI, F.; CERETTA, C. A.; BRUNETTO, G.; CERINI, J. B.; LOURENZI, C. R.; CONTI, L.; TIECHER, T. L.; SCHAPANSKI, D. E. Disponibilidade de nitrogênio de fontes minerais e orgânicas aplicadas em um Argissolo cultivado com videira. Revista Ceres, Viçosa-MG, v.61, n.2, p. 241-247, 2014. https://doi.org/10.1590/S0034737X2014000200012

MALAVOLTA, E. Nutrição mineral de plantas. São Paulo: Ed. Agr. Ceres, 2006.

MARQUES, M. O. Aspectos técnicos e legais da produção, transporte e aplicação de vinhaça. In: SEGATO, S. V.; PINTO, A. S.; JENDIROBA, E.; NÓBREGA, J. C. M. Atualização em produção de cana-de-açúcar. Piracicaba: Editorial, 2006. p. 369-375.

MARTINS, M. Y. A.; BARBOSA, K. de. P.; SILVA, P. C.; COSTA, R. A.; COSTA, da. A. R. Aplicação de diferentes doses de vinhaça sob 0 desenvolvimento vegetativo de plantas de milho. Enciclopédia Biosfera, Goiânia, v.9, n.16, p. 1-8, 2013.

NASCIMENTO, R. do.; SOUZA, J. A. de, MOREIRA, A.; MORAES, L. A. C. Phosphogypsum and vinasse application: soil chemical properties and alfalfa productivity and nutritional characteristics. Revista Caatinga, Mossoró, v.30, n.1, p. 213-219, 2017. https://dx.doi.org/10.1590/198321252017v30n123rc

NOVAIS, R. F.; ALVAREZ, V. H.; BARROS, N. F.; FONTES, R. L.; CANTARUTTI, R. B.; NEVES, J. L. Fertilidade do solo. Viçosa: Sociedade Brasileira de Ciência do Solo, 2007.

PEDROSA, T. D.; FARIAS, C. A. S. de.; PEREIRA, R. A.; FARIAS, E. T. do. R. Monitoramento dos parâmetros físico-químicos na compostagem de resíduos agroindustriais. Revista Nativa, Sinop, Campina Grande, v.1, n.1, p. 44-48, 2013. https://doi.org/10.14583/2318-7670.v01n01a08

PETTER, F. A.; SILVA, J. A.; PACHECO, L. P.; ALMEIDA, F. A.; ALCANTARA NETO, F.; ZUFFO, A. M.; LIMA, L. B. Desempenho agronômico da soja a doses e épocas de aplicação de potássio no cerrado piauiense. Revista de Ciências Agrárias Amazonian Journal of Agricultural And Environment of Sciences, Manaus, v.55, n.3, p. 190-196, 2012.

https://doi.org/10.4322/rca.2012.057

PRAVUSCHI, P. R.; MARQUES, P. A. A.; RIGOLIN, B. H. M.; SANTOS, A. C. P. Efeito de diferentes lâminas de irrigação na produção de óleo essencial do manjericão (Ocimum basilicum L.).

Acta Scientiarum Agronomy, Presidente Prudente, v. 32, n.4, p. 687-693. 2010.

http://dx.doi.org/10.4025/actasciagron.v32i4.316 $\underline{0}$.

RAIJ, B. V. Fertilidade do solo e adubação. Piracicaba: Potafos, 2001. 343 p.

RAIJ, B. V.; CANTARELLA, H.; QUAGGIO, J. A.; FURLANI, A. M. C. (Ed.). Recomendações de adubação e calagem para o Estado de São Paulo. 2. ed. Campinas: Instituto Agronômico de Campinas, Fundação IAC, 1997.

ROSOLEM, C. A.; CALONEGO, J. C.; FOLONI, J. S. S. Lixiviação de potássio da palhada de espécies de cobertura de solo de acordo com a quantidade de chuva aplicada. Revista Brasileira de Ciência do Solo, Viçosa, v.27, n.2, p. 355-362, 2003.

http://dx.doi.org/10.1590/s010006832003000200015.

REZENDE, J. O. Vinhaça: outra grande ameaça ao meio ambiente. Revista Magistra, Bahia, v.1, n.6, 1984.

SANTOS NETO, J. T.; LUCAS, F. T.; FRAGA, D. F.; OLIVEIRA, L. F.; PEDROSO NETO, J. C. Adubação nitrogenada, com e sem inoculação de semente, na cultura da soja. FAZU, s/v, n.10, p. 8-12, 2013.

SOUZA, J. K. C. de.; MESQUITA, F. de. O.; DANTAS NETO, J. D.; SOUZA, M. M. A. de.; FARIAS, C. H. de. A.; MENDES, H. C.; NUNES, R. M. de. A. Fertirrigação com vinhaça na produção de canade-açúcar. ACSA - Agropecuária Científica no Semiárido, Campina Grande, v.11, n.2, p. 7-12, 2015.

SCHLOTER, M.; DILLY, O.; MUNCH, J.C. Indicators for evaluating soil quality. Agriculture Ecosystems \& Environment, v.98, n.1, p. 255262, 2003. https://doi.org/10.1016/S01678809(03)00085-9 
UENO, C. R. J.; COSTA, A. C. S.; GIMESES, M. L.; ZANIN, G. M. Cultivo de alface com vinhaça submetida à biodigestão. In: VIII EPCC ENCONTRO INTERNACIONAL DE PRODUÇÃO CIENTÍFICA CESUMAR, 8., 2013, Maringá. Anais [...]. Maringá: CESUMAR, 2013. 5 p.

VIANA, E. M.; KIEHL, J. C. Doses de nitrogênio e potássio no crescimento do trigo. Bragantia, Campinas, v.69, n.4, p. 975-982, 2010.

https://doi.org/10.1590/s0006$\underline{87052010000400024}$

VIANA, E. M. Interação de nitrogênio e potássio na nutrição, no teor de clorofila e na atividade da redutase do nitrato de plantas de trigo. 2007. 96 f. Dissertação (Mestrado em Solos e Nutrição de Plantas) - Escola Superior de Agricultura Luiz de Queiroz, Universidade de São Paulo, Piracicaba, 2007.

VEGA, C. R. C.; SADRAS, V. O.; ANDRADE, F. H.; UHART, S. A. Reproductive allometry in soybean, maize and sunflower. Annals of Botany, v.85, n.4, p. 461-468, 2000.

https://doi.org/10.1006/anbo.1999.1084

XAVIER, T. F. Vinhaça in natura e biodigerida concentrada: efeitos nas características químicas e bioquímicas do solo e no crescimento inicial da cana-de-açúcar. 2012. 68 f. Tese (Doutorado em Agronomia - Ciência do Solo) - Faculdade de Ciências Agrárias e Veterinárias - Unesp, Jaboticabal, 2012.

ZAYAS, T.; RÓMERO, V.; SALGADO, L.; MERAZ, M.; MORALES, U. Applicability of coagulation/flocculation and electrochemical processes to the purification of biologically treated vinasse effluent. Separation and Purification Technology, Amsterdam, v.57, n.2, p. 270-276, 2007.

https://doi.org/10.1016/j.seppur.2007.04.019

ZILLI, J. É.; MARSON, L. C.; MARSON, B. F.; GIANLUPPI, V.; CAMPO, R. J.; HUNGRIA, M. Inoculação de Bradyrhizobium em soja por pulverização em cobertura. Pesquisa Agropecuária Brasileira, Brasília, v.43, n.4, p. 540 -545 , 2008. http://dx.doi.org/10.1590/50100204X2008000400014. 